\title{
An Improved Method for the Preparation of Silica Gel Media for Microbiological Purposes
}

\author{
By C. B. TAYLOR \\ I.C.I. Ltd., Butterwick Research Laboratories, The Frythe, Welroyn, \\ Hertfordshire
}

SUMMARY: A base exchange column for the preparation of silica sols is described. Sols prepared by the method can be sterilized by heat treatment and are stable for some weeks. Bacteriological media can easily be prepared with such sols and the gelling time regulated by the concentration of sodium chloride used.

For many microbiological purposes it is either essential or preferable to use media solidified by an inorganic gel; among inorganic gels only silica gels are at present practicable. The various published methods of preparing silica gels are far from satisfactory. Silica gel media are usually prepared by neutralizing sodium silicate with hydrochloric acid. In one modification the gel is allowed to set in a Petri dish and then washed for $24 \mathrm{hr}$. under running water and finally sterilized in a hot-air oven; the applications of this method are very restricted, and there is no guarantee that toxic substances are removed in the washing process. In another method the silicate-acid mixture is dialysed for several days through a membrane, and the purified product sterilized by filtration, gelation taking place rapidly after this operation; though the resulting gel is excellent the method is very time-consuming and tedious and the speed of gelation cannot be controlled.

A greatly improved method is possible by making the gel from a silica sol, removing the cations from sodium silicate by means of base-exchange material. To Joseph Crosfield and Sons Limited, I am greatly indebted for a supply of materials and for technical information which, with only minor modifications, is the basis of the method for preparing the sol described below. Media prepared with the silica sol supported excellent growth of all bacterial strains tested and a description of the methods may be of value to workers in various fields of microbiology.

\section{PRODUCTION OF THE SILICA SOL}

The base-exchange column

A glass tube of about 2 in. in diameter and $3 \mathrm{ft}$. long is held vertically by two large clamps (Pl. 1). At the base of the tube a plug of glass-wool is supported by short pieces of glass rod which rest on a tightly fitting rubber bung. A glass tube having a side arm and, below, a stop-cock is inserted up through the bung so that the top of the tube is level with the top of the bung. The tube is charged with 1 1. (approximately $1 \frac{3}{4} \mathrm{lb}$.) of 'Soucol', the baseexchanging material, leaving 10-12 in. of free space at the head of the column.

The bed of Soucol is graded by back-flushing with tap water through the side arm. This operation is repeated several times, draining the water till level with the top of the column of Soucol ('bed level') on each occasion. If the column 
separates during the back-flushing process the upper portion can be brought down most satisfactorily by a gentle rotational movement' produced by rocking the tube. The column should finally be quite free from air bubbles. The bed is then washed with 2 l. of distilled water, and having made certain that the flow from the discharge tube is not restricted, the liquid is drained to bed level.

The Soucol is regenerated by placing $300 \mathrm{ml}$. of $10 \%(\mathrm{v} / \mathrm{v})$ hydrochloric acid in the free portion above the bed and allowing it to flow at $c .50 \mathrm{ml} . / \mathrm{min}$. When bed level is reached a further $200 \mathrm{ml}$. of the acid is passed through. Finally the column is washed with 21 . or more of distilled water until the effluent is free of chlorides, and drained to bed level. If at any time either water or acid drains below bed level it is necessary to back-flush to remove air bubbles and repeat operations.

The concentration of sodium silicate used depends on the purpose for which the product is required, but a $3 \% \mathrm{SiO}_{2}$ sol is the most satisfactory for general purposes. Concentrations much greater than $3 \% \mathrm{SiO}_{2}$ should be avoided because the bed may become gelled.

Neutral sodium silicate $78 / 80$ degrees Twaddel containing $28.9 \% \mathrm{SiO}_{2}$ (Crosfield and Sons Ltd.) is diluted to a concentration of $812 \mathrm{~g} . / 3 \mathrm{l}$. of distilled water, and the solution passed through the bed at a speed of $100 \mathrm{ml} . / \mathrm{min}$. The first $500 \mathrm{ml}$. of the effluent, consisting largely of water, is discarded. The bed is then completely drained. It is advisable to test the $\mathrm{pH}$ of the effluent from time to time to ensure that it is acid. If it becomes alkaline the base exchange capacity of the bed is exhausted, perhaps because the Soucol was not properly regenerated. As the addition of cations will affect the gelling properties of the sol it is better to discard any alkaline sol or sols contaminated with such cations. The bed is then back-flushed and all air bubbles removed, washed down with 2 l. of distilled water, drained to bed level and regenerated. The sol produced should be perfectly clear and almost colourless.

An analysis of a prepared sol showed the following substances, expressed as p.p.m.: organic matter (as C), 185; Ca, 15; Mg, 10; $\mathrm{Pb}, 8 ; \mathrm{Zn}, 4 ; \mathrm{Cu},<1 ; \mathrm{P}_{2} \mathrm{O}_{5}, 2$.

\section{Preparation of media}

The only difficulty in using the silica sol in bacteriological media is the estimation of the time required to gel. As gelling depends, among other things, upon the strength of the sol, temperature, and the nature and concentration of the substance to be added, it is not possible to state precisely the method of preparing any particular medium. Small trial batches should be made until the correct conditions have been determined for setting the gel within the required period.

The sol, which has an initial $\mathrm{pH}$ value of $c$. 3.0, is stable over a period of at least 3 weeks, and becomes increasingly opaque with storage. It can be sterilized at $15 \mathrm{lb}$. pressure in an autoclave without affecting its gelling properties, but this operation decreases the acidity appreciably. The sol cannot, however, be adjusted to $\mathrm{pH} \mathrm{7.0}$ and subsequently sterilized, because this procedure destroys the gelling power. Moreover, if the sol has not been properly freed from cations it will gel during autoclaving. Although gelling can be obtained by adding the 
usual salts present in peptones and meat extracts, the process is slow, and it is advisable to control gelling time by suitable concentrations of sodium chloride. If desirable, an ammonium gel can be formed by the addition of ammonium compounds, such as $\left(\mathrm{NH}_{4}\right)_{2} \mathrm{SO}_{4}$. When rapid gelling is not required, as in the preparation of slopes, stab cultures, or for the inoculation of the surface of media in Petri plates the addition of $0.1 \% \mathrm{NaCl}$ will allow peptone-yeast extract medium to gel in approximately $2 \mathrm{hr}$. when the $\mathrm{SiO}_{2}$ content is $1.5 \%$. When plate counts are to be carried out and gelling is required within 10-20 min. the concentration of $\mathrm{NaCl}$ required may be as great as $0.5 \%$, but this will depend upon the nature and concentration of the ingredients; a simple salt medium containing appreciable amounts of certain salts, particularly ammonium salts, will gel rapidly.

It is essential to sterilize the silica sol separately from the ingredients of the medium. To prepare a litre of any medium the total quantities of salts and other ingredients are dissolved in $250 \mathrm{ml}$. of distilled water and adjusted to the required $\mathrm{pH}$ value. The amount of $\mathrm{N}-\mathrm{NaOH}$ required to adjust $750 \mathrm{ml}$. of the sterilized sol is determined, and this amount added as excess to the $250 \mathrm{ml}$. of solution containing the ingredients. The two sterilized solutions are mixed when required, and the necessary amounts pipetted into plugged sterilized tubes or into Petri dishes. When colony counts are to be made, smaller quantities are mixed, sufficient for 3-4 plates. Very satisfactory results have been obtained by preparing $15 \mathrm{ml}$. of sol and $5 \mathrm{ml}$. of nutrients separately in test tubes. The measured amount of fluid is placed in the Petri dish and mixed with the sol. The nutrients are then added, and after thorough mixing, the dish is allowed to stand for $\mathbf{1 ~ h r}$. before inverting. Properly prepared plates require no drying and can be inverted in the incubator in the usual manner. For counts in milk, soil or polluted water, it should be possible to incorporate the $\mathrm{NaCl}$ in the dilution fluid and thus eliminate the danger of the medium gelling before use. For semi-solid media a final $\mathrm{SiO}_{2}$ content of $0.5-0.75$ is satisfactory; for slopes the concentration should be at least $2.5 \%$.

The easy manner in which silica sol can be produced, its stability during storage and autoclaving suggest that, with ingenuity, the microbiologist can use silica sol for many purposes in the cultivation of micro-organisms. My occasional failures in preparation have invariably been due to the production of an incorrect sol, either by the use of a sodium silicate other than the brand stated above, or of an exhausted bed of Soucol.

It should be noted that a patent has been filed in Britain for the production of silica sols by passage through carbonaceous base-exchange material by the National Aluminate Corporation of America.

\section{EXPLANATION】OF PLATE}

Base-exchange column for preparation of silica sols.

(Received 9 September 1949) 
Journal of General Microbiology, Vol. 4, No. 2

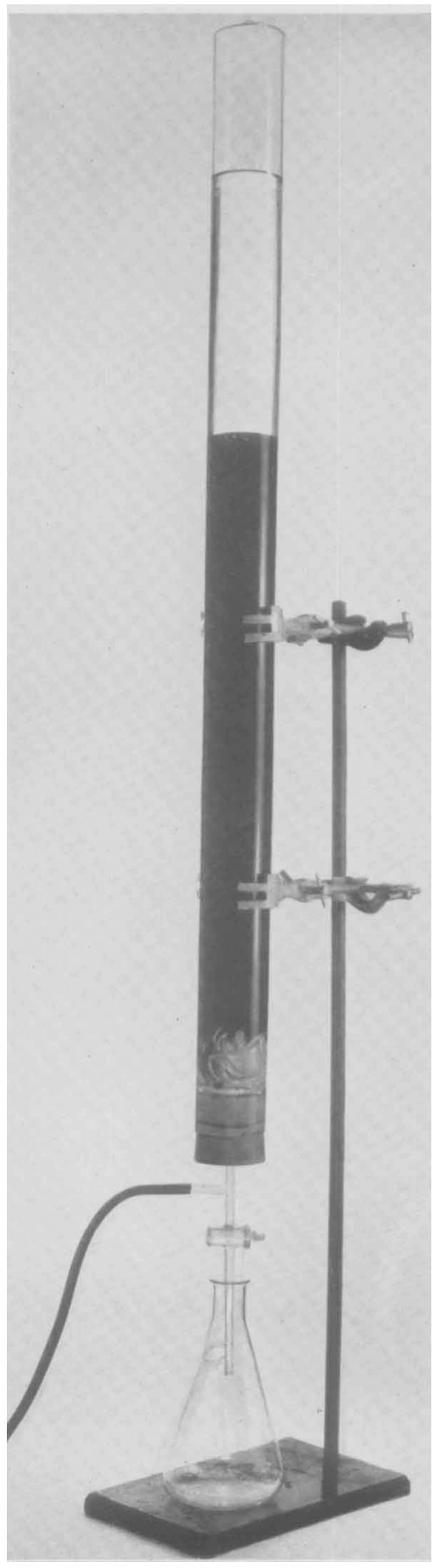

C. B. Taylor-Silica gel for media. Plate 1 